\title{
Studying the possibility of obtaining heat-insulating building materials based on lime carbonization hardening and rice husk
}

\author{
Vitaliy Nikolaenko ${ }^{1 *}$, Nikolai Lyubomirskiy ${ }^{1}$,Elena Nikolaenko $^{1}$, and Aleksandr Bakhtin ${ }^{1}$ \\ ${ }^{1}$ V.I. Vernadsky Crimean Federal University, 4 Academician Vernadsky, Simferopol 295007, Russian Federation
}

\begin{abstract}
The paper presents studies of changes in the physicomechanical properties of samples based on lime-limestone compositions with rice husk filler hardening in an environment with a high concentration of carbon dioxide. The samples are semi-dry pressing cylinders made of a mixture of hydrated lime, ground limestone and a filler in the form of rice husk in order to reduce the density and increase the heatinsulation ability of building materials based on this raw material mixture. The studies showed that there is an increase in the strength of the samples due to the transition of portlandite to calcite during forced carbonization. The possibility of using waste products of plant origin by the example of rice husk in the production technology of heat-insulating building materials using artificial forced carbonization which will allow obtain products with the following characteristics: compressive strength $2.2-4.0 \mathrm{MPA}$ at a density of $700-1200 \mathrm{~kg} / \mathrm{m}^{3}$, thermal conductivity $-0.11-0.13 \mathrm{~W} / \mathrm{m} \bullet \mathrm{K}$, has been proved.
\end{abstract}

\section{Introduction}

An integral part of any industrial production is the production of a large number of by-products which are accumulated in the dumps or released into the atmosphere as gaseous waste. These materials often contain undesirable compounds and their deposition is a serious social problem with the impact on the environment and human health.

In view of the current environmental situation, all sorts of decisions to conserve natural resources and reduce the level of air pollution by various industrial wastes are of vital importance. The analysis of the problem state shows that for most industrial and agricultural industries waste generation is characteristic with a low degree of their use which affects the increase in the area of dumps.

Processing plant products is no exception as well. For example, the processing of 1 ton of rice produces about 200 $\mathrm{kg}$ of waste in the form of rice husk.

About 600 million tons of rice husk is produced annually in the world as a result of threshing [1]. For the most part, it is burned in furnaces or buried requiring the use of large land. But the most interesting thing is that the husk does not decay in the ground due to the presence of silicon dioxide in it. And when burning husks, substances are released that can adversely affect the nature and human health. Disposal of rice husk is an urgent problem throughout the world, especially in countries where rice is the main cereal product (China, India, Egypt, South Korea, African countries and partially Russia, Uzbekistan).

The resulting husk is widely used and can be disposed in many ways. However, most methods of utilization of rice husk are associated with pyrolysis (to obtain ash) and the release of a large number of caustic gaseous products that pollute the atmosphere and harm human health [2-6].

The problem of disposal of the above wastes can be solved through their use in the production of heat-insulating building materials reminiscent of arbolite in structure. The use of eco-materials from agricultural waste is an increasingly common solution in the field of construction. This necessitates the development of research in the field of obtaining economical and environmentally friendly building materials and the introduction of developed resourcesaving technologies in production.

In addition, climate change on the planet due to the annual increase of the amount of $\mathrm{CO}_{2}$ emitted by industrial enterprises requires new technological solutions for the disposal of gaseous waste [7].

In this regard, it is relevant to study the use of $\mathrm{CO}_{2}$ in the technology of building materials based on technogenic lime binder and limestone waste with a filler of plant origin in order to utilize by-products of production and reduce carbon dioxide emissions into the atmosphere.

As a result of the transition of hydrated lime to calcium carbonate, the material is hardened, its water resistance and frost resistance increase. The durability of calcareous materials is proven by time because a large number of ancient architectural monuments were built using precisely lime mortars and limestone stones (palaces of the ancient city of Knossos of XVII - XV centuries BC on the island of Crete, St. Sophia Cathedral in Kiev of XI century AD, ancient defensive buildings and structures on the coast of Lisbon, the Great Wall of China, etc. [8]). However, this process is

\footnotetext{
* Corresponding author: author@email.org
} 
lengthy and can take years or even decades. It can be intensified by forced carbonization of materials based on lime due to the disposal of specially prepared flue gases from lime kilns [9-12].

The authors of the article obtained the optimal parameters for producing carbonized calcareous-carbonate building wall materials formed by means of semi-dry pressing [13-16]. A new direction in the study of materials based on lime carbonization hardening is the production of heat-insulating materials due to the introduction of fillers that increase porosity and lower the density of finished products.

In order to give the materials greater heat-insulation potential, it was decided to introduce a rice husk filler into the composition of the lime-limestone compositions. In addition, according to modern views, the structure of the material does not remain unchanged but continuously undergoes changes in space and time under the influence of both external and internal factors $[17,18]$ which makes it possible to predict an increase in the strength of products over time.

The aim of this work is to study the changes in the physicomechanical properties of forced carbonized samples based on lime, limestone filler and filler of plant origin in the form of rice husk.

\section{Materials and methods}

The study of the properties of the proposed material was carried out on samples-cylinders with a diameter of $125 \mathrm{~mm}$ pressed onto a screw mechanical press. The raw mix was a composition of slaked lime, sieved through a sieve with a mesh size of $0.63 \mathrm{~mm}$, ground limestone with a specific surface of $1700 \mathrm{~cm}^{2} / \mathrm{g}$ and rice husk crushed in a special device to a specific surface of $2400 \mathrm{~cm}^{2} / \mathrm{g}$. Dry raw materials were mixed with water. In the preparation of samples, the percentage of raw materials and the moisture content of the raw mix were varied. The carbonization of the pressed-in products was carried out in a tooling by supplying carbon dioxide of $100 \%$ concentration to the screw press housing for 5 minutes.

To study the effect of organic compounds contained in rice husks on the course of the forced carbonization process, cylinder samples with a diameter of $30 \mathrm{~mm}$ were formed by the method of semi-dry pressing (pressing pressure - 30 $\mathrm{MPa}$ ). In this case, the raw material mixture was a composition of lime sifted through a sieve with a mesh size of 0.63 $\mathrm{mm}$, a marble-like limestone of fractionated composition and a special solution obtained by digesting plant waste (rice husks, wood shavings, and straw). Extracts from plant waste were obtained by digesting the waste in boiling water and further filtering the resulting broth. To assess the effect of the presence of organic compounds in the grinder of the raw material mixture, samples mixed with plain water were also formed. Forced carbonization of these samples was carried out in a special carbonization chamber [19] for 60 minutes.

Studies were carried out on changes in the phase composition of secondary calcite obtained by forced carbonization of samples from a raw mixture mixed with decoctions of plant waste using a thermogravimetric derivatographic analysis on STA 8000 synchronous analyzer (TGA/DSC/DTA) (PerkinElmer (USA). Chemical analysis of rice husk was carried out using X-ray fluorescence analysis on Epsilon 3XLE ED spectrometer (PANalytical).

The physicomechanical characteristics of the test samples were measured using standard methods for determining the compressive strength and coefficient of thermal conductivity.

\section{The main section with the results and their analyses}

Studies on the qualitative effect of organic additives contained in plant waste (rice husk, sawdust, and straw) showed that mixing the original composition of slaked lime and fractionated limestone with the resulting broths does not negatively affect the course of the forced carbonization process. As can be seen from the obtained thermograms, at the end of the forced carbonization process, practically no free portlandite remains in the cylinder samples (Fig. 1).

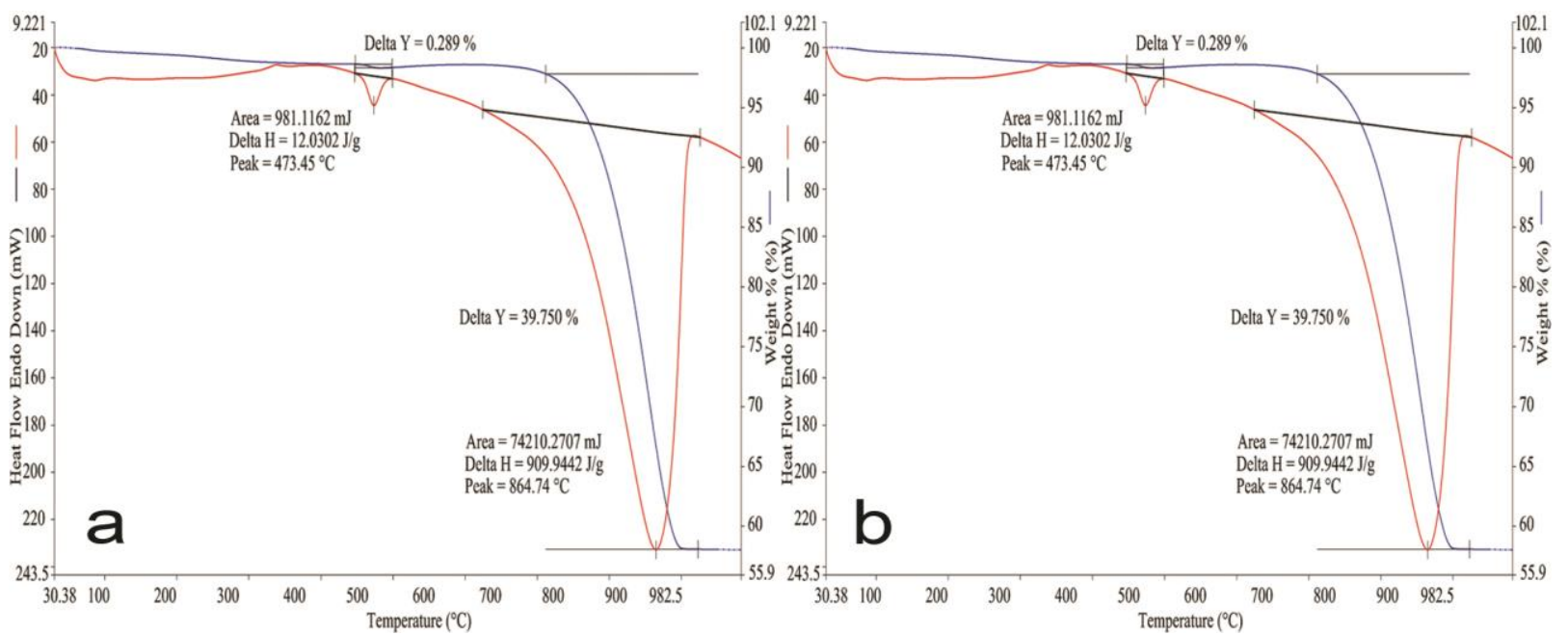

Fig. 1. Thermograms of the samples: a) control sample mixed with water; b) sample mixed with a decoction of rice husk. 
Physicomechanical characteristics also indicate the absence of a negative effect on the process of forced carbonization (Table 1).

Table 1. Physicomechanical characteristics of the samples obtained by mixing with water and extracts from waste of plant origin (rice husk, sawdust, and straw).

\begin{tabular}{|c|c|c|c|c|}
\hline \multirow{2}{*}{$\begin{array}{c}\text { Raw mixture } \\
\text { (as a percentage of dry } \\
\text { weight) }\end{array}$} & \multirow{2}{*}{ Type of fluid } & \multicolumn{3}{|c|}{ Physicomechanical characteristics } \\
\hline & & $\mathrm{R}_{\mathrm{pr}}, \mathrm{MPa}$ & $\rho, \mathrm{kg} / \mathrm{m}^{3}$ & $\Delta \mathrm{m}, \mathrm{g}$ \\
\hline \multirow{4}{*}{$\begin{array}{c}\text { Lime }(10 \%) \\
+ \\
\text { Limestone }(90 \%)\end{array}$} & Water & 38.5 & 1913 & 2.037 \\
\hline & Extract of rice husk & 40.3 & 1910 & 2.041 \\
\hline & Extract of sawdust & 39.6 & 1917 & 2.032 \\
\hline & Extract of straw & 39.1 & 1913 & 2.021 \\
\hline
\end{tabular}

In the future, we decided to use rice husk for research for several reasons.

Firstly, rice husk contains starch particles (10-15\%) left over from rice grains which, in turn, contains amylopectin a polysaccharide that promotes the growth of smaller particles of secondary calcite in comparison with natural lime carbonization in the presence of water. Studies on the effect of introducing rice broth into lime mortar during the construction of the Great Wall of China indicate an improvement in the physicomechanical properties of the mortar [20,21].

Secondly, in the case of burning rice husk, carbon dioxide is formed which is a necessary component for the formation of secondary calcite during forced carbonization, and the resulting ash can act as a filler in the structure of the material.

Changes in the physicomechanical properties of the samples obtained from the composition of lime, limestone and rice husk are shown in Table 2.

Table 2. Physicomechanical properties of the samples.

\begin{tabular}{|c|c|c|c|c|c|c|c|}
\hline \multicolumn{4}{|c|}{ Composition of the dry raw mix, $\%$} & \multirow{2}{*}{$\begin{array}{c}\text { Humidity, } \\
\%\end{array}$} & \multirow{2}{*}{$\begin{array}{c}\Delta \mathrm{m}, \\
\mathrm{g}\end{array}$} & \multirow{2}{*}{$\begin{array}{c}\rho, \\
\mathrm{kg} / \mathrm{m}^{3}\end{array}$} & \multirow{2}{*}{$\begin{array}{l}\mathrm{R}_{\mathrm{pr}} \\
\mathrm{MPa}\end{array}$} \\
\hline $\mathrm{Ca}(\mathrm{OH})_{2}$ & $\mathrm{CaCO}_{3}$ & Rice husk & Proportion & & & & \\
\hline 15 & 75 & \multirow{3}{*}{10} & $1: 5$ & \multirow{3}{*}{20} & 87.6 & 1267 & 3.3 \\
\hline 18 & 72 & & $1: 4$ & & 90.8 & 1230 & 4.2 \\
\hline 22.5 & 67.5 & & $1: 3$ & & 106.2 & 1211 & 4.6 \\
\hline 13.3 & 66.7 & \multirow{3}{*}{20} & $1: 5$ & \multirow{3}{*}{20} & 51.8 & 1095 & 3.1 \\
\hline 16 & 64 & & $1: 4$ & & 68.4 & 1051 & 3.6 \\
\hline 20 & 60 & & $1: 3$ & & 101.2 & 1000 & 4.9 \\
\hline 11.7 & 58.3 & \multirow{3}{*}{30} & $1: 5$ & \multirow{3}{*}{22} & 23.6 & 863 & 2.6 \\
\hline 14 & 56 & & $1: 4$ & & 46.5 & 830 & 2.7 \\
\hline 17.5 & 52.5 & & $1: 3$ & & 62.3 & 801 & 3.2 \\
\hline 10 & 50 & \multirow{3}{*}{40} & $1: 5$ & \multirow{3}{*}{24} & 29.5 & 754 & 1.8 \\
\hline 12 & 48 & & $1: 4$ & & 38.0 & 731 & 2.0 \\
\hline 15 & 45 & & $1: 3$ & & 80.1 & 716 & 2.4 \\
\hline
\end{tabular}

As it can be seen from the data in Table 2, there is a regular increase in weight due to the transition of portlandite to calcite, i.e. the carbonization reaction takes place and after opening the press-tool, the sample does not crumble which indicates the successful operation of lime carbonization hardening as a binder matrix with a filler. The strength of the samples decreases with an increase in the amount of rice husk filler introduced, while the density, respectively, with the introduction of a larger amount of rice husk decreases which favorably affects the heat-insulation properties of the obtained material - the heat conductivity of a material with $40 \%$ rice husk content lies in within the range of $0.11-0.13$ $\mathrm{W} / \mathrm{m} \cdot \mathrm{K}$, which, along with a strength of $2.5 \mathrm{MPa}$, makes it possible to classify it as a structural and heat-insulating material.

It should be noted that the introduction of $30 \%$ and $40 \%$ of the rice husk into the samples during testing of the samples leads to non-fragile destruction (the samples are deformed before destruction). In this regard, the compressive strength of the samples at given fractions of rice husks was determined when the $10 \%$ deformation of the samples was achieved in height.

Figure 2 shows a destroyed sample with the shown qualitative reaction of calcium hydroxide to phenolphthalein. As it can be seen from the photo, the sample still contains a significant amount of portlandite particles that have not reacted with CO2. This fact allows us to assert that the experimental samples have a certain potential for further carbonate hardening and, consequently, to increase their strength characteristics. It is known [13-16] that the strength characteristics of carbonate hardening materials largely depend on the degree of carbonization of the calcareous component. We can say that five minutes of forced carbonization is not enough for these samples, i.e. the processing 
time of samples based on a lime-limestone composition and rice husk should be increased or more intensive methods of their forced carbonization should be applied. However, even with such a treatment time with carbon dioxide, a heatinsulating material is obtained which complies with the requirements of regulatory documents in terms of strength and heat-transfer properties.
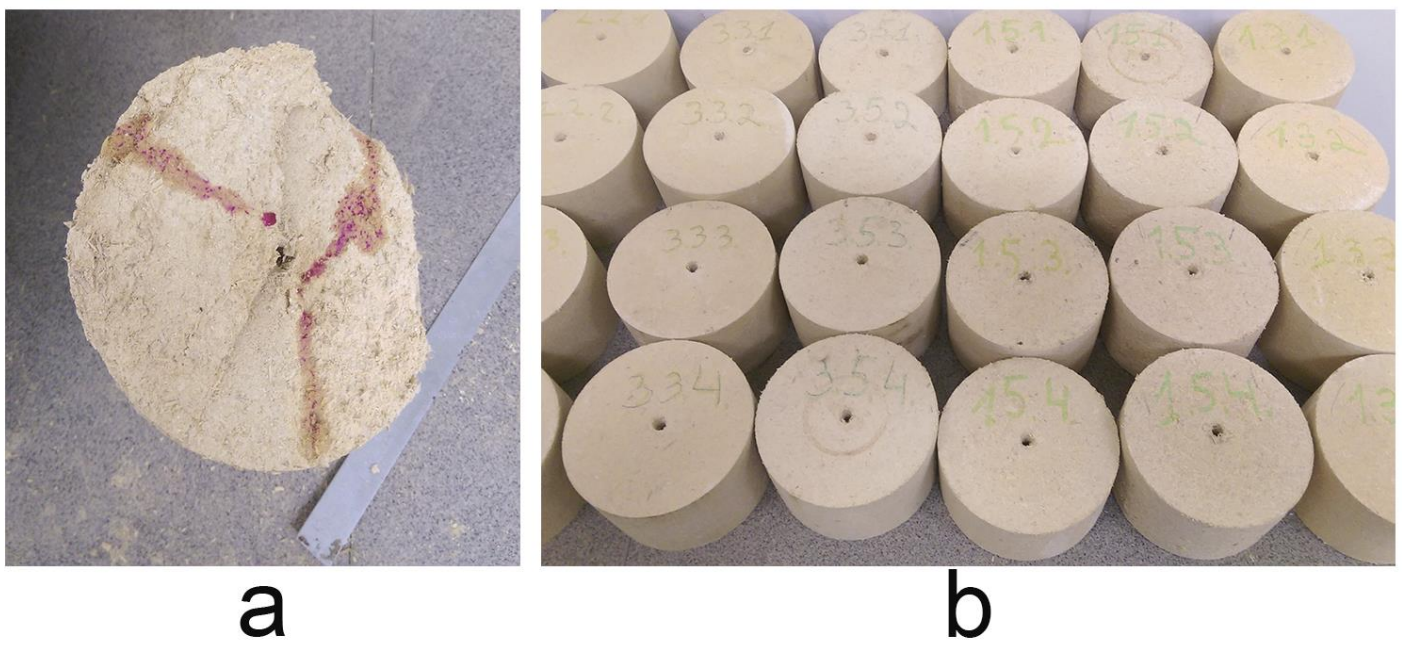

Fig. 2. General view of the destroyed sample stained with phenolphthalein (a). A series of samples prepared for testing (b).

\section{Conclusion}

As a result of the studies, the possibility of obtaining heat-insulating building materials based on compositions of lime, limestone and rice husk treated with carbon dioxide gas of $100 \%$ concentration was established. The results obtained show the possibility of obtaining products with a strength of 2.2 to $4.0 \mathrm{MPa}$ at a density of $700-1200 \mathrm{~kg} / \mathrm{m}^{3}$ with a thermal conductivity coefficient in the range of $0.11-0.13 \mathrm{~W} / \mathrm{m} \cdot \mathrm{K}$.

The proposed type of material has been little studied and has many directions for research on optimizing the raw material composition and materials used: the use of lime-containing industrial wastes such as lime dust [17,22,23] or carbide lime; studying the effect of starch compounds of rice husks on the structure formation of the material; studying changes in the strength of products over time and etc.

The production of this material is one of the possible ways to solve the problems of pollution of the atmosphere and the environment by involving various industrial waste in the process of creating building materials.

This work was partially supported by the V.I. Vernadsky Crimean Federal University Development Program for 2015-2024.

\section{References}

1. Information from Food and agriculture organization of the United Nations website http://www.fao.org

2. M. Chabannes, J.-C. Bénézet, L. Clerc, E. Garcia-Diaz, Use of raw rice husk as natural aggregate in a lightweight insulating concrete: an innovative application, Construction and Building Materials 70, pp. 428-438 (2014)

3. M.M. Younes, H.A. Abdel-Rahman, Magdy M. Khattab, Utilization of rice husk ash and waste glass in the production of ternary blended cement mortar composites, Journal of Building Engineering 20, pp. $42-50$ (2018)

4. E. Chabi, A. Lecomte, E.C. Adjovi, A. Dieye, A. Merlin, Mix design method for plant aggregates concrete: example of the rice husk, Construction and Building Materials 174, pp. 233-243 (2018)

5. R.L. Reaño, Assessment of environmental impact and energy performance of rice hus utilization in various biohydrogen production pathways, Bioresource Technology 299 (2019)

6. T.-H. Liou, P.-Y. Wang, Utilization of rice husk wastes in synthesis of graphene oxide-based carbonaceous nanocomposites, Waste Management 108, pp. 51-61 (2020)

7. Information from the European Commission's of climate strategies and targets website https://ec.europa.eu/clima/policies/strategies/

8. C. Borges, A. Santos Silva, R. Veiga, Durability of ancient lime mortars in humid environment, Construction and Building Materials 66, pp. 606-620 (2014)

9. H. Pöllmann, Mineralogical Strategies to reduce CO2 in the fabrication of alternative cements Proc., IBAUSIL, 1, pp. 110-129 (2015)

10. D.R. Moorehead, Cementation by the carbonation of hydrated lime, Cement and Concrete research, 16, pp. 700-708 (1986)

11. P.De Silva, L. Bucea, D.R. Moorehead, V. Sirivivatnanon, Carbonate binders: Reaction kinetics, strength and microstructure, Cement \& Concrete Composites 28, pp. 613-620 (2006)

12. K. Van Balen, D. Van Gemert, Modelling lime mortar carbonation, Materials and Structures 27, pp. 393-398 (1994) 
13. N.V. Lyubomirskiy, S.I. Fedorkin, A.S. Bakhtin, T.A. Bakhtina, T.V. Lyubomirskaya, Research in influence of regimes of forced carbonate hardening on properties of materials on the basis of lime-limestone compositions of semidry pressing, Stroitel'nye materialy 8 , pp. 7-12 (2017)

14. S.I. Fedorkin, N.V. Lyubomirskiy, M.A. Lukyanchenko, System based on lime of carbonizing hardening Constr. Mater. 11, pp. $45-47$ (in Russian)

15. N.V. Lyubomirskiy, S.I. Fedorkin, The influence of carbon dioxide pressure on the kinetics of forced carbonation of limestone semi-dry pressing and the formation of its strength, Construction and technogenic safety 3 (2016), pp. 2838 (in Russian)

16. N.V. Lyubomirskiy, A.S. Bakhtin, T.A. Bakhtina, E. Yu. Nikolaenko, V.V. Nikolaenko, Influence of calcium bicarbonate on the structure and properties of materials based on lime carbonation hardening, International research journal 11-4, pp. 86-93 (2016) (in Russian)

17. V. Nikolaenko, N.V. Lyubomirskiy, E. Nikolaenko, Changes in the physicomechanical properties of materials of carbonate hardening on the basis of lime and lime stone systems with the course of time, Materials Today: Proceedings, 5-19, pp. 1917-1921 (2019)

18. N.V. Lyubomirskiy, A.S. Bakhtin, T.A. Bakhtina, Change of physical and mechanical properties of limecarbonate calcium materials of forced carbonate hardening in time, Construction and technogenic safety 8, pp. 67-73 (2017).

19. S. I. Fedorkin, N. V. Lyubomirskiy, V. G. Nosatov, T.A. Loktionova, Automatic installation and technique of studying of process of carbonization of lime, Construction and technogenic safety 19-20, pp. 74-78 (2007)

20. Y. Fuwei, Z. Bingjian, M. Qinglin, Study of Sticky Rice-Lime Mortar Technology for the Restoration of Historical Masonry Construction, Accounts of Chemical Research 6-43, pp. 936-944 (2010).

21. W. Shanwei, W. Sheliang, L. Zhe, Y. Wenjuan, L. Bo, L. Binbin, Characterization of sticky-rice lime binders from old masonry relics in north China: The primary contribution for conservation, Construction and Building Materials, 250 (2020)

22. M.A. Latifa, S. Naganathanb, H.A. Razakc, K. N. Mustaphab, Performance of lime kiln dust as cementitious material, Procedia Engineering 125, pp. 780 - 787 (2015)

23. A. Arulrajah, A. Mohammadinia, A. D'Amico, S. Horpibulsuk, Effect of lime kiln dust as an alternative binder in the stabilization of construction and demolition materials, Construction and Building Materials 152, pp. 999-1007 (2017) 